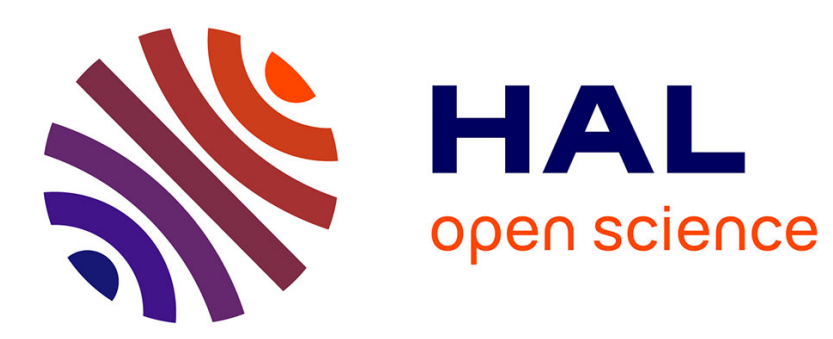

\title{
Comparative analysis between impact factor and h-index for pharmacology and psychiatry journals
}

Pascal Bador, Thierry Lafouge

\section{To cite this version:}

Pascal Bador, Thierry Lafouge. Comparative analysis between impact factor and h-index for pharmacology and psychiatry journals. Scientometrics, 2010, 84 (1), pp.65-79. hal-00588760

\section{HAL Id: hal-00588760 \\ https://hal.science/hal-00588760}

Submitted on 23 Jun 2011

HAL is a multi-disciplinary open access archive for the deposit and dissemination of scientific research documents, whether they are published or not. The documents may come from teaching and research institutions in France or abroad, or from public or private research centers.
L'archive ouverte pluridisciplinaire HAL, est destinée au dépôt et à la diffusion de documents scientifiques de niveau recherche, publiés ou non, émanant des établissements d'enseignement et de recherche français ou étrangers, des laboratoires publics ou privés. 


\title{
Comparative analysis between impact factor and $\mathrm{h}$-index for pharmacology and psychiatry journals
}

\author{
Pascal Bador ${ }^{\mathrm{a},{ }^{*}}$, Thierry Lafouge ${ }^{\mathrm{b}}$
}

a. Université de Lyon, Lyon, F-69008, France ; Université Lyon 1, équipe ELICO, ISPB-Faculté de Pharmacie, 8 avenue Rockefeller, Lyon cedex 08, F-69373, France.

b. Université de Lyon, Lyon, F-69008, France ; Université Lyon 1, équipe ELICO, 43 boulevard du 11 Novembre 1918, Villeurbanne, F-69622, France

* Corresponding author at: Centre de Documentation Pharmaceutique, Equipe ELICO, ISPB-Faculté de Pharmacie, Université Lyon 1, 8 avenue Rockefeller, F-69373 Lyon cedex 08, France.

E-mail addresses: pascal.bador@univ-lyon1.fr (P. Bador), thierry.lafouge@univ-lyon1.fr (T. Lafouge)

\begin{abstract}
Using strictly the same parameters (identical two publication years (2004-2005) and identical one-year citation window (2006)), IF 2006 was compared with h-index 2006 for two samples of "Pharmacology and Pharmacy" and "Psychiatry" journals computed from the ISI Web of Science. For the two samples, the IF and the $h$-index rankings of the journals are very different.

The correlation coefficient between the IF and the h-index is high for Psychiatry but lower for Pharmacology.

The linearity test performed between the $\mathrm{h}$-index and $I F^{\frac{\alpha}{\alpha+1}} \cdot n^{\frac{1}{\alpha+1}}$ showed the great sensitivity of the model compared with $\alpha$.

The IF and h-index can be completely complementary when evaluating journals of the same scientific discipline.
\end{abstract}

\section{Keywords}

Journal Impact Factor, Hirsch index, Journal ranking

\section{Introduction}

The Thomson Scientific journal Impact Factor (IF) [GARFIELD , 1955] is well known for being the document measure of journal impact. IF is often used to rank scientific journals, despite several recognised limitations well summarized by CURTIS and HUNTER [2006], DELAVALLE et al. [2007], DONG et al. [2005], HECHT et al. [1998].

HIRSCH [2005] recently suggested a new research performance indicator that is designed for application at the micro level. The Hirsch-Index, or h-index, quantifies as a single-number criterion the scientific output of a single researcher. The $h$-index is a very simple new measure incorporating both quantity and visibility of publications [BORNMANN and DANIEL, 2007]: "A scientist has index $h$ if $h$ of his or her $N_{p}$ papers have at least $h$ citations each and the other $\left(N_{p}-h\right)$ papers have fewer than $\leq \mathrm{h}$ citations each" [HIRSCH, 2005]. For example h-index of 20 means that the scientist has published 20 papers that each had at least 20 citations. 
BRAUN et al. [200"6] proposed that the h-index could be usefully applied to the citation analysis of journals, as well. The $\mathrm{h}$-index for evaluating the scientific impact of journals as a robust alternative indicator can be an advantageous complement to journal IF. The journal h-index is calculated as follows: "Retrieving all source items of a given journal from a given year and sorting them by the number of times cited, it is easy to find the highest rank number which is still lower than the corresponding 'Times Cited' value. This is exactly the h-index of the journals for the given year" [BRAUN et al., 2006].

In order to progress in the IF/h-index comparison analysis, this study compares IF and h-index using exactly and strictly the same parameters (identical two publication years (2004-2005) and identical one-year citation window (2006)). Hence, we propose here to compare IF 2006 and what we call h-index 2006 for two samples of "Pharmacology and Pharmacy" and "Psychiatry" journals taken from the Journal Citation Reports (JCR) 2006.

\section{Methods}

\subsection{Constitution of the two samples}

We ranked the 199 journals of the "Pharmacology and Pharmacy" section of the JCR 2006 drawn from the Web of Science in descending order of IF and we took the first 50 journals to constitute our first sample. We proceeded in the same way to constitute our second sample of 50 journals coming from the "Psychiatry" section (94 journals) of the JCR 2006.

In order to strictly compare their IF and h-index using the same data, we wanted to work on all the citations obtained in 2006 by the articles published in 2004-2005 in the 50 journals of our two samples of "Pharmacology and Psychiatry" and "Psychiatry".

\subsection{Calculation of h-index 2006}

The IF was easily extracted from the JCR 2006 in June 2008 whereas h-index 2006 was calculated manually in July 2008 for each of the 50 journals of our two samples in the following way:

- 1) Search for articles of 2004

- 2) We displayed the references citing each article obtained ("Times Cited" link)

- 3) Using the window obtained and the "Refine Results" function, we extracted the number of articles of 2006 (Citations 2006) from the "Publication Years" menu

- 4) The same procedure for the articles of 2005

Thus, for each of the 100 journals, we compiled a table similar to the one shown in table 1 for the journal "Annual Review of Pharmacology and Toxicology". We then identified the h-index 2006 corresponding to the number $h$ of articles published in 2004-2005 and cited at least $h$ times during 2006.

\section{Please insert Table 1: Calculation of the h-index 2006}

Also, for all the articles of 2004-2005 published in the 100 journals, we identified the number of "Reviews" using the "Refine Results" function and the "Document Types" menu. We thus calculated the percentage of Reviews compared with the total number of articles published in 20042005.

2.3. Correlation between the $\mathrm{h}$-index and the impact factor

We studied the statistical correlation between the IF and h-index. For this, we calculated Pearson's correlation coefficient. If the result of the test was negative, we classified journals characterised (IF, h-index) by two different numerical values (reduced central values) into four groups around an average value. 
Let $I F_{i}$ journal's impact factor, $i=1, \ldots N, \overline{I F}$ and $\sigma_{I F}$ average and standard deviation

Let $H_{i}$ journal's h-index $i, i=1, \ldots N ; \bar{H}$ and $\sigma_{H}$ average and standard deviation

In order to make this ranking, we calculate the $Z$ standard scores (reduced central values) of

$I F_{i} H_{i} i=1, N$

$$
\begin{aligned}
& Z_{I F_{i}}=\frac{I F_{i}-\overline{I F}}{\sigma_{I F}} i=1, N \\
& Z_{H_{i}}=\frac{H_{i}-\bar{H}}{\sigma_{H}} \quad i=1, N
\end{aligned}
$$

Let axis $x$, impact factor, and axis $y$,h-index

The four groups are:

- First quarter: $x>0 \quad y>0$ high h-index, high impact factor

- Second quarter: $x<0 \quad y>0$ high h-index, low impact factor

- Third quarter: $x<0 \quad y<0$ low h-index, low impact factor

- Fourth quarter: $x>0 \quad y<0$ low h-index, high impact factor

2.4. The laws of information and the $h$-index

We recall the theoretical background obtained in recent papers ([GLANZEL, 2006] and [SCHUBERT et al., 2007]). The authors interpret, theoretically, relationships between the $h$-index and $\mathrm{IF}$, given the underlying citation distribution, on the basis of extreme values statistics.

Let $X$ be a random variable. $X$ represents the citation rate of a paper. $n$ is a given sample with distribution $X$. The question is how the $\mathrm{h}$-index of a journal is determined by the parameters of $X$, its expected value (IF) and $n$, the number of papers published in the journal.

For $k \gg>1$ we suppose the distribution of the random variable $X$ is a discrete Paretian distribution with finite expectation

$$
P(X=k) \approx b \cdot k^{-(\alpha+1)} \text { where } \alpha>1 \text { and } b \text { positive constant }
$$

hence

$$
G(X>k) \approx c k^{-\alpha} \text { where } c \text { is a positive constant }
$$

Using Gumbel's r-th characteristic extreme value $u_{r}$ Schubert et al. define the theoretical h-index $H$ :

$$
H \equiv \operatorname{Max}\left\{r: u_{r} \geq r\right\} \text { where } u_{r} \equiv G^{-1}\left(\frac{r}{n}\right)=\operatorname{Max}\left\{k: G(k) \geq \frac{r}{n}\right\}
$$

Since $X$ is Paretian (2) and by elementary manipulations of (3) hence we have:

$$
H=u_{H} \approx m \cdot\left(\frac{n}{r}\right)^{\frac{1}{\alpha}}
$$

Applying the Hirsh condition $H=r$ to (4):

$$
H=\approx m\left(\frac{n}{H}\right)^{\frac{1}{\alpha}} \quad m \text { is a positive constant }
$$


The expected value of the Pareto distribution (1) (impact factor) IF is:

$$
I F=\frac{d}{\alpha-1} \quad d \text { is a positive constant }
$$

while the constant $d=m$ hence (5) (6) implies the principal result of their theoretical background

$$
H \approx d^{\frac{\alpha}{\alpha+1}} \cdot n^{\frac{1}{\alpha+1}}
$$

Schubert et al. use (6) in the special case of $\alpha=2$. We do not support this hypothesis.

Hence (6) (7) implies

$$
H=a I F^{\frac{\alpha}{\alpha+1}} \cdot n^{\frac{1}{\alpha+1}} \quad \text { where } a \text { is a positive constant }
$$

\section{Results}

Tables 2A and 2B present the data obtained (IF 2006, h-index 2006, number of articles published in 2004-2005, percentage of articles that are reviews), respectively for our sample of 50 journals from "Pharmacology and Pharmacy" and for our sample of 50 journals from "Psychiatry", both coming from JCR 2006 and ranked in descending order of IF 2006. We see that the ranking would obviously be different if we took into account the descending order of h-index 2006. For example, in table 2A, the journal "Antimicrobial Agents and Chemotherapy" ranked thirtieth with IF 2006 (IF = 4.143), was ranked third with h-index 2006 (h-index $2006=19)$, equal to the journal "Annual Review of Pharmacology and Toxicology" (itself ranked first in the IF 2006 ranking, IF $2006=$ 22.808). In table 2B, the journal "Psychopharmacology" ranked twenty-fourth with IF 2006 (IF $2006=$ 3.625), was ranked seventh with h-index 2006 (h-index $2006=15$ ), equal to the journals "British Journal of Psychiatry" (whose IF ranking - seventh - did not change) and "Schizophrenia Research" (itself ranked fourteenth in the IF 2006 ranking, IF $2006=4.264$ ).

Please insert Table 2A: Impact Factor 2006 ranked list of the 50 first Pharmacology and Pharmacy journals

Please insert Table 2B: Impact Factor 2006 ranked list of the $\mathbf{5 0}$ first Psychiatry journals

One can see that 7 journals are common to the 2 samples studied: Neuropsychopharmacology, International Journal of Neuropsychopharmacology, Journal of Clinical Psychopharmacology, CNS Drugs, European Neuropsychopharmacology, Psychopharmacology, Journal of Psychopharmacology ranked with IF 2006 respectively at $12^{\text {th }}, 20^{\text {th }}, 24^{\text {th }}, 29^{\text {th }}, 39^{\text {th }}, 42^{\text {nd }}$ and $47^{\text {th }}$ in the "Pharmacology and Pharmacy" section, were ranked respectively $5^{\text {th }}, 8^{\text {th }}, 10^{\text {th }}, 15^{\text {th }}, 21^{\text {st }}$, $24^{\text {th }}$ and $26^{\text {th }}$ in the "Psychiatry" section.

As a complement, to illustrate the data in tables $2 \mathrm{~A}$ and $2 \mathrm{~B}$ in graph form, we present figures $1 A$ and $1 B$, which show the ranking of the two samples in descending order of $h$-index 2006.

Please insert Figure 1A: Comparison of IF 2006 and h-index 2006 for Pharmacology and Pharmacy journals (h-index ranking)

Please insert Figure 1B: Comparison of IF 2006 and h-index 2006 for Psychiatry journals (h-index ranking)

Figure $1 \mathrm{~A}$ shows a decrease in h-index 2006, revealing 16 steps and therefore 16 groups of "Pharmacology and Pharmacy" journals whose h-index varies from 30 to 5 . The h-index 2006 is much higher than the IF 2006 (up to 4 times higher), but with four exceptions: Annual Review of 
Pharmacology and Toxicology, Pharmacological Reviews, Reviews of Physiology Biochemistry and Pharmacology, and Critical Reviews in Therapeutic Drug Carrier Systems. These four journals have the characteristic that they publish very few articles (respectively 52, 48, 32, and 21 articles in 2 years) but only reviews. We can see that in our sample of 50 journals, 15 journals (meaning $30 \%$ ) have published between $89 \%$ and $100 \%$ of articles in the form of reviews.

Figure 1B also reveals 16 steps and therefore 16 groups of "Psychiatry" journals whose $h$ index varies from 27 to 5 . In this second sample, the h-index 2006 is always, and without exception, much higher than the IF 2006 (here also up to 4 times higher for the Psychopharmacology journal). The "Psychiatry" journals publish many less articles in the form of reviews: only two journals (4\%), Mental Retardation and Developmental Disabilities Research Reviews, and Progress in Neuropsychopharmacology and Biological Psychiatry, respectively published $100 \%$ and $94 \%$ of reviews.

For the "Pharmacology and Pharmacy" journals, we obtained a low correlation coefficient of 0.59 , which we considered as insignificant. We then categorized the journals and rated them using the method based on the reduced centred coordinates. This way of categorizing is shown in figure 2 . Thus, the journals were spread over four quarters, the composition of which is given in table 3 . Quarter 1 of the journals, showing the highest IF 2006 and h-index 2006, represents the journals that published the most reviews (on average $71 \%$ of the articles) against respectively an average of $22 \%$ for quarter 2, 50\% for quarter 3 and $35 \%$ for quarter 4 .

\section{Please insert Figure 2: Standard scores of IF 2006 and h-index 2006 for Pharmacology and} Pharmacy journals

\section{Please insert Table 3: Pharmacy and Pharmacology journals}

For the "Psychiatry" journals, we obtained a high correlation coefficient of 0.88 . In figure 3 , we show the scatter plot and the associated linear regression line.

\section{Please insert Figure 3: Correlation of IF 2006 and h-index 2006 for Psychiatry journals}

In order to systematically test the validity of $\mathrm{Eq}(8), H(y)$ was plotted against the product ${ }_{I F}{ }^{\frac{\alpha}{\alpha+1}} \cdot n^{\frac{1}{\alpha+1}}$ ( $x$ ) using data from the two collections.

To calculate the parameter $a$ of (8) we consider the linear regression line for different values of $\alpha$ close to 2. We choose the value of $\alpha$ that gives the best adjustment (Figure 4A, Figure 4B).

Pharmacy journals

$$
\begin{array}{ll}
\alpha=2 & y=0.6508 x+1.1187 \\
\alpha=2.2 & y=0.7055 x+1.0384 \\
\alpha=2.3 & y=0.7273 \quad x+1.1386
\end{array}
$$

Psychiatry journals

$$
\begin{array}{lll}
\alpha=2.4 & y=0.7715 x+0.9709 & R^{2}=0.9577 \\
\alpha=2.5 & y=0.7962 x+0.9981 & R^{2}=0.9577 \\
\alpha=2.6 & y=0.82 x+1.0278 & R^{2}=0.9573
\end{array}
$$




\section{Please insert Figure 4A: Correlation of the $h$-index with $\mathrm{n}^{1 /(2.2+1)} \mathrm{IF}^{2.2 /(2.2+1)}$ for Pharmacology and Pharmacy journals}

\section{Please insert Figure 4B: Correlation of the $h$-index with $n^{1 /(2.5+1)} \mathrm{IF}^{2.5 /(2.5+1)}$ for Psychiatry journals}

For psychiatry, we studied the variation of $a$ according to $\alpha$ with a coefficient of determination remaining higher than 0.93 (Figure 4C).

Please insert Figure 4C: Variation of $a$ and $\mathbf{R}^{2}$ according to $\alpha$

\section{Discussion}

The interest and originality of our study was, to our knowledge for the first time, to compare rankings based on IF 2006 and h-index 2006, using strictly the same data based on the usual definition of IF (identical two publication years 2004-2005 and identical one-year citation window 2006) for two samples of journals of the health field. The study by SCHUBERT et al. [2007] is based on strictly the same parameters as well, but particularly on one publication year and on a three-year citation window beginning with the publication year for both the journal impact measure and the $h$ index. The results given in tables $2 \mathrm{~A}$ and $2 \mathrm{~B}$ show that, for the "Pharmacology and Pharmacy" journals and the "Psychiatry" journals, the two rankings are completely different. The IF allows a ranking using a customary descending order starting from the values of the JCR given to the nearest thousandth. However, the $h$-index offers a decreasing ranking starting from values that are integers. Therefore, the $\mathrm{h}$-index ranking is much less fine and precise and reveals steps (figures $1 \mathrm{~A}$ and $1 \mathrm{~B}$ ) each corresponding to a group of journals with the same h-index. We thus reveal 16 groups for our two samples. Also, the amplitude of the $\mathrm{h}$-index values is higher ( 25 for "Pharmacology and Pharmacy", 22 for "Psychiatry") than that for the IF values (approximately 20 for "Pharmacology and Pharmacy", approximately 12 for "Psychiatry"). Furthermore, we must note that for a given journal the h-index is generally higher than the IF (up to 4 times higher), which was seen in our two samples. Only four journals of the "Pharmacology and Pharmacy" section have an IF higher or equal to the hindex. Moreover, these four journals specializing exclusively in the publication of reviews have the characteristic of publishing a very low annual number (a maximum of around fifty) of this type of article.

Also, the "Pharmacology and Pharmacy" section has the characteristic of having a very big percentage of journals specializing in the publication of reviews. These journals are those that very often present the best IF, which is logical since their review articles are more often cited than the original articles. However, ranking based on the h-index is not very sensitive to the percentage of reviews published.

The "Psychiatry" section has very few journals specializing in the publication of reviews, which makes this type of data not very important for comparing the IF and h-index.

Thus, from our two samples presenting different characteristics as regards the publication of reviews, we cannot deduce any influence from this parameter on the IF and h-index. Therefore, this parameter is not significant for comparing the two rankings.

The second part of this comparative study of the IF and h-index concerned the analysis of their correlation coefficient. Thus, we noted a high correlation for the "Psychiatry" sample. However, the low correlation, considered as insignificant between the IF and h-index of the journals in the "Pharmacology and Pharmacy" sample, led us to try to propose a categorization for it using the traditional method of reduced centred coordinates. The representation thus obtained, figure 2 , shows four groups (quarters) of journals. Quarter 1, the most outstanding, includes the ten journals presenting both the highest IF 2006 and h-index 2006. The important fact that we can draw from this 
representation is that this group contains the journals that publish by far the highest percentage (71\%) of articles in the form of reviews, which seems completely logical.

During the linearity test between the $\mathrm{h}$-index and $I F^{\frac{\alpha}{\alpha+1}} \cdot n^{\frac{1}{\alpha+1}}$ we showed the great sensitivity of the model compared with $\alpha$. In fact, as regards psychiatry, if we consider that the linear relationship remains acceptable up to a coefficient of determination of $93 \%$, we can vary $\alpha$ between 1.6 and 4.2, which varies the slope of the straight line between 0.53 and 1.1! Furthermore, we can see that the variation of $a$ according to $\alpha$ is approximately linear. We think that these many adjustments represent the different parameters of adjustment of distribution of articles in each journal. It is remarkable that we find a value close to that found by SCHUBERT and al. [2007], who found 0.75 by taking the sizes of corpuses, all sciences combined, of 6000 or specific fields such as chemistry or biology. We also thought it interesting to take a single corpus by merging our two samples: we obtained the best adjustment $\left(R^{2}=0.94\right)$ for $\alpha=2.2$ with a slope of 0.71 . This result still seems to confirm Schubert's, meaning a coefficient $a$ independent of the scientific field and an optimum value of $\alpha$ very nearly 2, meaning a Pareto coefficient law close to 3 . Unlike Schubert's results, we do not have a zero intercept point, but a point close to 1 . This can be explained by the fact that we took only the 50 journals with the highest IF and thus a minimum h-index of 5 . In theory, the equation (8) is only valid for the extreme values.

More generally, and as shown in our study of two very small samples, the rating of journals starting from the $h$-index may represent an interesting and complementary alternative to the wellknown rating based on the IF. In fact, the h-index rating proposes a categorization of journals (several journals capable of having the same $h$-index) making it possible to create classes of journals with the same h-index: e.g. class 5 , class 6 , class 7 ... class 19 , class 25 . It is evident that, to have a meaning, this ranking must be made as for IF, within a collection of comparable journals of the same wellidentified scientific discipline. In order to put this new type of ranking into perspective, we could certainly propose to display beside the value of each class the maximum value found for the journal obtaining the best $\mathrm{h}$-index for the discipline studied, using the following model:

journal $x \rightarrow h$-index $=6 / 25$

journal $Y \rightarrow h$-index $=19 / 25$

meaning that journal $X$ is characterized by an $h$-index of 6 and journal $Y$ by an $h$-index of 19, with the note that the journals rated first of the discipline studied have an h-index of 25.

This type of ranking by classes of journal is often appreciated and used by experts and scientific committees of evaluation as shown by VANCLAY [2008] in the study proposing a ranking of forestry journals based on an evaluation of the journals by experts and also on their $h$-index.

As shown by BRAUN et al. [2006], for a given journal, the h-index presents different and useful characteristics compared with the IF. Firstly, h-index is insensitive to an accidental excess of uncited papers and also to one or several outstandingly highly cited papers; secondly, it combines the effects of "quantity" (number of publications) and "quality" (citation rate) in a rather specific balanced way that should reduce the apparent "overrating" of some review journals.

The h-index could be very interesting and a complementary tool of IF if it would not be calculated for a "life-time contribution" as suggested by HIRSCH [2005] for individual scientists, but for a definite period as we did in this study with the same parameters as IF 2006. In our study, IF and h-index were exactly and strictly comparable and thus complementary in the rating of journals of the same discipline.

BRAUN et al. [2006], who worked on 2001 as source year (one publication year), had to eliminate the first and second journals of the $2001 \mathrm{IF}$ list. Since these journals published 24 and 23 papers, respectively, in 2001, they had no chance to compete with the chart toppers (obviously the h-index cannot be larger than the number of papers it is based on). If we take a two publication year period as in our study, all journals will have published enough articles (probably at least fifty) and this will avoid having to possibly eliminate some journals having very high IF because they published a very low number of articles. 
As suggested by ROUSSEAU [2006], one might also consider calculating a relative $\mathrm{h}$-index by dividing it by the yearly number of articles of the journal, which could be another research lead for the assessment of the different ranking methods of scientific journals.

Some questions are open about the link to Pareto's law. For example, how can we interpret the linear variation of $a$ according to $\alpha$.

\section{References}

BORNMANN L. and DANIEL H. (2007). What do we know about the $h$ index? Journal of the American Society for Information Science and Technology, 58(9), 1381-1385.

BRAUN T., GLANZEL W. and SCHUBERT A. (2006). A Hirsch-type index for journals. Scientometrics, 69(1), 169-173.

CURTIS W. and HUNTER J. (2006). What the impact factor means for surgery journals. World Journal of Surgery, 30, 1368-1370.

DELAVALLE R., SCHILLING L., RODRIGUEZ M., VAN DE SOMPEL H. and BOLLEN J. (2007). Refining dermatology journal impact factors using pagerank. Journal of the American Academy of Dermatology, 57, 116-119.

DONG P., LOH M. and MONDRY A. (2005). The "impact factor" revisited. Biomedical Digital Libraries, 2, 7, doi: 10.1186/1742-5581-2-7.

GARFIELD E. (1955). Citation indexes to science: a new dimension in documentation through association of ideas. Science, 122, 108-111.

GLANZEL W. (2006). On the h-index - A mathematical approach to a new measure of publication activity and citation impact. Scientometrics, 67(2), 315-321.

HECHT F., HECHT B. and SANDBERG A. (1998). The journal impact factor: A misnamed, misleading, misused measure. Cancer Genetics and Cytogenetics, 104, 77-81.

HIRSCH J. (2005). An index to quantify an individual's scientific research output. Proceedings of the National Academy of Sciences, 102, 16569-16572.

ROUSSEAU R. (2006). A case study: Evolution of JASIS' h-index. Science Focus, 1( 1), 16-17.

SCHUBERT A. and GLANZEL W. (2007). A systematic analyse of Hirsch-type indices for journals. Journal of Informetrics, 1, 179-184.

VANCLAY J. (2008). Ranking forestry journals using the h-index. Journal of informetrics, 2, 326-334. 
Table 1: Calculation of the h-index 2006

\begin{tabular}{|c|c|c|c|}
\hline \multicolumn{4}{|c|}{ Annual Review of Pharmacology and Toxicology } \\
\hline Articles 2004* & Citations 2006 & Articles 2005* & Citations 2006 \\
\hline 1 & 17 & 1 & 16 \\
\hline 2 & 33 & 2 & 7 \\
\hline 3 & 21 & 3 & 109 \\
\hline 4 & 11 & 4 & 36 \\
\hline 5 & 14 & 5 & 18 \\
\hline 6 & 6 & 6 & 5 \\
\hline 7 & 18 & 7 & 23 \\
\hline 8 & 23 & 8 & 6 \\
\hline 9 & 49 & 9 & 0 \\
\hline 10 & 18 & 10 & 11 \\
\hline 11 & 67 & 11 & 14 \\
\hline 12 & 26 & 12 & 12 \\
\hline 13 & 6 & 13 & 19 \\
\hline 14 & 28 & 14 & 6 \\
\hline 15 & 25 & 15 & 12 \\
\hline 16 & 33 & 16 & 21 \\
\hline 17 & 49 & 17 & 8 \\
\hline 18 & 27 & 18 & 5 \\
\hline 19 & 18 & 19 & 10 \\
\hline 20 & 33 & 20 & 15 \\
\hline 21 & 17 & 21 & 54 \\
\hline 22 & 54 & 22 & 0 \\
\hline \multirow[t]{7}{*}{23} & 17 & 23 & 3 \\
\hline & & 24 & 4 \\
\hline & & 25 & 18 \\
\hline & & 26 & 33 \\
\hline & & 27 & 12 \\
\hline & & 28 & 17 \\
\hline & & 29 & 19 \\
\hline 13 papers cited & it least 19 times & 8 papers cited & t least 19 times \\
\hline \multicolumn{4}{|c|}{ Total: 21 papers $2004-2005$ cited at least 19 times } \\
\hline 13 papers cited & t least 20 times & 6 papers cited & t least 20 times \\
\hline \multicolumn{4}{|c|}{ Total: 19 papers $2004-2005$ cited at least 20 times } \\
\hline \multicolumn{4}{|c|}{ h-index $=19$} \\
\hline
\end{tabular}


Table 2A: Impact Factor 2006 ranked list of the 50 first Pharmacology and Pharmacy journals

\begin{tabular}{|c|c|c|c|c|c|}
\hline $\begin{array}{l}\text { IF } 2006 \\
\text { ranking }\end{array}$ & $\begin{array}{l}\text { Abbreviated } \\
\text { Journal Title }\end{array}$ & $\begin{array}{c}\text { IF } \\
2006 \\
\end{array}$ & $\begin{array}{c}\text { h-index } \\
2006\end{array}$ & $\begin{array}{l}\mathrm{Nb} \text { articles } \\
2004-2005\end{array}$ & $\begin{array}{c}\% \\
\text { Reviews } \\
\end{array}$ \\
\hline 1 & ANNU REV PHARMACOL & 22.808 & 19 & 52 & 100 \\
\hline 2 & NAT REV DRUG DISCOV & 20.970 & 30 & 135 & 63 \\
\hline 3 & PHARMACOL REV & 16.854 & 17 & 48 & 100 \\
\hline 4 & TRENDS PHARMACOL SCI & 10.400 & 21 & 190 & 64 \\
\hline 5 & PHARMACOL THERAPEUT & 8.657 & 15 & 137 & 97 \\
\hline 6 & CLIN PHARMACOL THER & 8.066 & 16 & 212 & 2 \\
\hline 7 & ADV DRUG DELIVER REV & 7.977 & 18 & 217 & 100 \\
\hline 8 & PHARMACOGENETICS & 7.221 & 13 & 95 & 1 \\
\hline 9 & MED RES REV & 7.218 & 11 & 55 & 69 \\
\hline 10 & DRUG DISCOV TODAY & 7.152 & 15 & 243 & 98 \\
\hline 11 & CURR OPIN PHARMACOL & 6.916 & 17 & 179 & 76 \\
\hline $12^{*}$ & NEUROPSYCHOPHARMACOL* & 5.889 & 16 & 468 & 6 \\
\hline 13 & CURR DRUG METAB & 5.762 & 11 & 80 & 100 \\
\hline 14 & DRUG METAB REV & 5.754 & 9 & 61 & 69 \\
\hline 15 & REV PHYSIOL BIOCH P & 5.625 & 5 & 32 & 100 \\
\hline 16 & PHARMACOGENET GENOM & 5.391 & 11 & 87 & 6 \\
\hline 17 & CURR PHARM DESIGN & 5.270 & 16 & 588 & 100 \\
\hline 18 & DRUG RESIST UPDATE & 5.268 & 9 & 56 & 99 \\
\hline 19 & CURR MED CHEM & 5.207 & 15 & 382 & 93 \\
\hline $20^{*}$ & INT J NEUROPSYCHOPH* & 5.184 & 9 & 114 & 10 \\
\hline 21 & CRIT REV THER DRUG & 5.000 & 5 & 21 & 100 \\
\hline 22 & ANTIVIR THER & 4.982 & 11 & 228 & 9 \\
\hline 23 & TOXICOL APPL PHARM & 4.722 & 16 & 472 & 15 \\
\hline $24^{*}$ & J CLIN PSYCHOPHARM* & 4.561 & 10 & 171 & 4 \\
\hline 25 & DRUGS & 4.472 & 14 & 337 & 58 \\
\hline 26 & MOL PHARMACOL & 4.469 & 16 & 765 & 2 \\
\hline 27 & CURR OPIN DRUG DISC & 4.319 & 11 & 138 & 100 \\
\hline 28 & CURR DRUG TARGETS & 4.274 & 10 & 146 & 100 \\
\hline $29 *$ & CNS DRUGS* & 4.210 & 11 & 157 & 50 \\
\hline 30 & ANTIMICROB AGENTS CH & 4.153 & 19 & 1621 & 1 \\
\hline 31 & CLIN PHARMACOKINET & 4.115 & 12 & 156 & 99 \\
\hline 32 & CONTROL CLIN TRIALS & 4.025 & 6 & 40 & 8 \\
\hline 33 & J CONTROL RELEASE & 4.012 & 14 & 678 & 3 \\
\hline 34 & PHARMACOGENOMICS J & 3.957 & 9 & 92 & 8 \\
\hline 35 & J PHARMACOL EXP THER & 3.956 & 17 & 1240 & 0 \\
\hline 36 & J ANTIMICROB CHEMOTH & 3.891 & 17 & 780 & 6 \\
\hline 37 & NEUROPHARMACOLOGY & 3.860 & 15 & 513 & 3 \\
\hline 38 & BRIT J PHARMACOL & 3.825 & 15 & 767 & 5 \\
\hline $39 *$ & EUR NEUROPSYCHOPHARM* & 3.794 & 10 & 160 & 6 \\
\hline 40 & DRUG SAFETY & 3.673 & 9 & 165 & 48 \\
\hline 41 & DRUG METAB DISPOS & 3.638 & 13 & 461 & 1 \\
\hline $42 *$ & PSYCHOPHARMACOLOGY* & 3.625 & 15 & 801 & 5 \\
\hline 43 & PHARMACOGENOMICS & 3.603 & 11 & 136 & 51 \\
\hline 44 & BIOCHEM PHARMACOL & 3.581 & 15 & 873 & 1 \\
\hline 45 & CNS DRUG REV & 3.474 & 6 & 38 & 89 \\
\hline 46 & ALIMENT PHARM THERAP & 3.287 & 14 & 773 & 23 \\
\hline $47^{*}$ & J PSYCHOPHARMACOL* & 3.255 & 8 & 149 & 14 \\
\hline 48 & INT J IMMUNOPATH PH & 3.213 & 9 & 127 & 8 \\
\hline 49 & EUR J PHARM BIOPHARM & 3.185 & 11 & 270 & 10 \\
\hline 50 & EXPERT OPIN INV DRUG & 3.174 & 12 & 242 & 72 \\
\hline
\end{tabular}

*journals belonging to both JCR sections : «Pharmacology and Pharmacy» and «Psychiatry» 
Table 2B: Impact Factor 2006 ranked list of the 50 first Psychiatry journals

\begin{tabular}{|c|c|c|c|c|c|}
\hline $\begin{array}{l}\text { IF } 2006 \\
\text { ranking }\end{array}$ & $\begin{array}{l}\text { Abbreviated } \\
\text { Journal Title }\end{array}$ & $\begin{array}{c}\text { IF } \\
2006 \\
\end{array}$ & $\begin{array}{c}\text { h-index } \\
2006 \\
\end{array}$ & $\begin{array}{r}\text { Nb articles } \\
2004-2005 \\
\end{array}$ & $\begin{array}{c}\% \\
\text { Reviews }\end{array}$ \\
\hline 1 & ARCH GEN PSYCHIAT & 13.936 & 27 & 233 & 3 \\
\hline 2 & MOL PSYCHIATR & 11.804 & 21 & 204 & 20 \\
\hline 3 & AM J PSYCHIAT & 8.250 & 25 & 592 & 49 \\
\hline 4 & BIOL PSYCHIAT & 7.154 & 22 & 635 & 5 \\
\hline $5 *$ & NEUROPSYCHOPHARMACOL* & 5.889 & 16 & 468 & 6 \\
\hline 6 & J CLIN PSYCHIAT & 5.533 & 16 & 552 & 19 \\
\hline 7 & BRIT J PSYCHIAT & 5.436 & 15 & 326 & 25 \\
\hline $8^{*}$ & INT J NEUROPSYCHOPH* & 5.184 & 9 & 114 & 10 \\
\hline 9 & J AM ACAD CHILD PSY & 4.767 & 13 & 287 & 41 \\
\hline $10^{*}$ & J CLIN PSYCHOPHARM* & 4.561 & 10 & 171 & 4 \\
\hline 11 & AM J MED GENET B & 4.463 & 14 & 298 & 1 \\
\hline 12 & SCHIZOPHRENIA BULL & 4.352 & 9 & 122 & 11 \\
\hline 13 & PSYCHOTHER PSYCHOSOM & 4.333 & 9 & 93 & 4 \\
\hline 14 & SCHIZOPHR RES & 4.264 & 15 & 503 & 3 \\
\hline $15^{*}$ & CNS DRUGS* & 4.210 & 11 & 157 & 50 \\
\hline 16 & J PSYCHIATR NEUROSCI & 4.100 & 10 & 70 & 26 \\
\hline 17 & ADDICTION & 4.088 & 11 & 319 & 11 \\
\hline 18 & ACTA PSYCHIAT SCAND & 3.857 & 11 & 258 & 13 \\
\hline 18 & PSYCHOSOM MED & 3.857 & 11 & 287 & 6 \\
\hline 20 & PSYCHOL MED & 3.816 & 11 & 299 & 5 \\
\hline $21^{*}$ & EUR NEUROPSYCHOPHARM* & 3.794 & 10 & 160 & 6 \\
\hline 22 & J PSYCHIATR RES & 3.700 & 9 & 140 & 2 \\
\hline 23 & J NEUROL NEUROSUR PS & 3.630 & 13 & 700 & 3 \\
\hline $24^{*}$ & PSYCHOPHARMACOLOGY* & 3.625 & 15 & 801 & 5 \\
\hline 25 & BIPOLAR DISORD & 3.494 & 11 & 156 & 23 \\
\hline $26^{*}$ & J PSYCHOPHARMACOL* & 3.255 & 8 & 149 & 14 \\
\hline 27 & DRUG ALCOHOL DEPEN & 3.213 & 10 & 300 & 8 \\
\hline 28 & J AFFECT DISORDERS & 3.138 & 12 & 456 & 4 \\
\hline 29 & INT CLIN PSYCHOPHARM & 3.080 & 8 & 113 & 5 \\
\hline 30 & EUR ARCH PSY CLIN N & 3.042 & 8 & 120 & 5 \\
\hline 31 & AM J GERIAT PSYCHIAT & 2.894 & 8 & 198 & 5 \\
\hline 32 & PHARMACOPSYCHIATRY & 2.849 & 6 & 119 & 7 \\
\hline 33 & PSYCHIAT RES-NEUROIM & 2.755 & 8 & 151 & 2 \\
\hline 34 & MENT RETARD DEV D R & 2.671 & 8 & 82 & 100 \\
\hline 35 & PROG NEURO-PSYCHOPH & 2.584 & 11 & 320 & 94 \\
\hline 36 & DEPRESS ANXIETY & 2.549 & 8 & 113 & 5 \\
\hline 37 & CAN J PSYCHIAT & 2.531 & 6 & 192 & 23 \\
\hline 38 & DEMENT GERIATR COGN & 2.511 & 9 & 223 & 3 \\
\hline 39 & GEN HOSP PSYCHIAT & 2.500 & 7 & 118 & 0 \\
\hline 40 & J CHILD ADOL PSYCHOP & 2.486 & 7 & 148 & 8 \\
\hline 41 & PSYCHIAT SERV & 2.430 & 9 & 316 & 0 \\
\hline 42 & HUM PSYCHOPHARM CLIN & 2.386 & 7 & 127 & 19 \\
\hline 43 & J INT NEUROPSYCH SOC & 2.367 & 9 & 188 & 7 \\
\hline 43 & NEUROPSYCHOBIOLOGY & 2.367 & 7 & 158 & 2 \\
\hline 45 & J PSYCHOSOM RES & 2.322 & 8 & 273 & 0 \\
\hline 46 & PSYCHIAT RES & 2.310 & 9 & 303 & 1 \\
\hline 47 & COMPR PSYCHIAT & 2.181 & 7 & 138 & 2 \\
\hline 48 & WORLD J BIOL PSYCHIA & 2.094 & 5 & 53 & 30 \\
\hline 49 & CNS SPECTRUMS & 2.051 & 7 & 175 & 53 \\
\hline 50 & EPILEPSY BEHAV & 2.026 & 8 & 345 & 14 \\
\hline
\end{tabular}

*journals belonging to both JCR sections : «Pharmacology and Pharmacy» and «Psychiatry» 
Table 3: Pharmacy and Pharmacology journals

\begin{tabular}{l|l}
\hline Quarter $\mathbf{1}: \mathbf{1 0}$ journals & Quarter $\mathbf{3}: \mathbf{2 3}$ journals \\
\hline ANNU REV PHARMACOL & ANTIVIR THER \\
ADV DRUG DELIVER REV & CLIN PHARMACOKINET \\
CLIN PHARMACOL THER & CNS DRUG REV \\
CURR OPIN PHARMACOL & CNS DRUGS \\
DRUG DISCOV TODAY & CRIT REV THER DRUG \\
NAT REV DRUG DISCOV & CURR DRUG METAB \\
NEUROPSYCHOPHARMACOL & CURR DRUG TARGETS \\
PHARMACOL REV & CURR OPIN DRUG DISC \\
PHARMACOL THERAPEUT & DRUG METAB DISPOS \\
TRENDS PHARMACOL SCI & DRUG METAB REV \\
\hline QUarter $\mathbf{2}: \mathbf{1 5}$ jOURnals & DRUG RESIST UPDATE \\
\hline ALIMENT PHARM THERAP & DRUG SAFETY \\
ANTIMICROB AGENTS CH & EUR J PHARM BIOPHARM \\
BIOCHEM PHARMACOL & EUR NEUROPSYCHOPHARM \\
BRIT J PHARMACOL & EXPERT OPIN INV DRUG \\
CONTROL CLIN TRIALS & INT J IMMUNOPATH PH \\
CURR MED CHEM & INT J NEUROPSYCHOPH \\
CURR PHARM DESIGN & J CLIN PSYCHOPHARM \\
DRUGS & J PSYCHOPHARMACOL \\
J ANTIMICROB CHEMOTH & PHARMACOGENET GENOM \\
J CONTROL RELEASE & PHARMACOGENOMICS \\
J PHARMACOL EXP THER & PHARMACOGENOMICS J \\
MOL PHARMACOL & REV PHYSIOL BIOCH P \\
\cline { 2 - 2 } NEUROPHARMACOLOGY & QUarter 4 : 2 jOURAIS \\
PSYCHOPHARMACOLOGY & MED RES REV \\
TOXICOL APPL PHARM & PHARMACOGENETICS \\
\hline
\end{tabular}




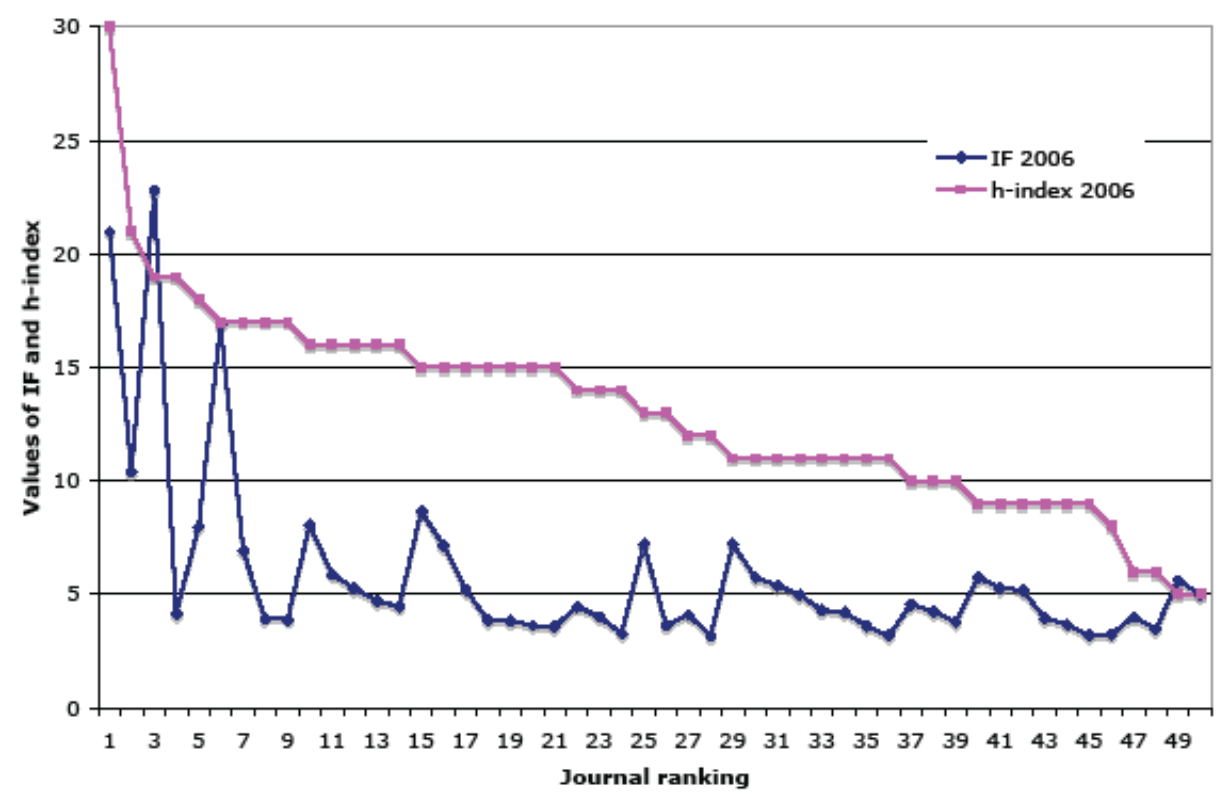

Figure 1A: Comparison of IF 2006 and h-index 2006 for Pharmacology and Pharmacy journals (hindex ranking) 


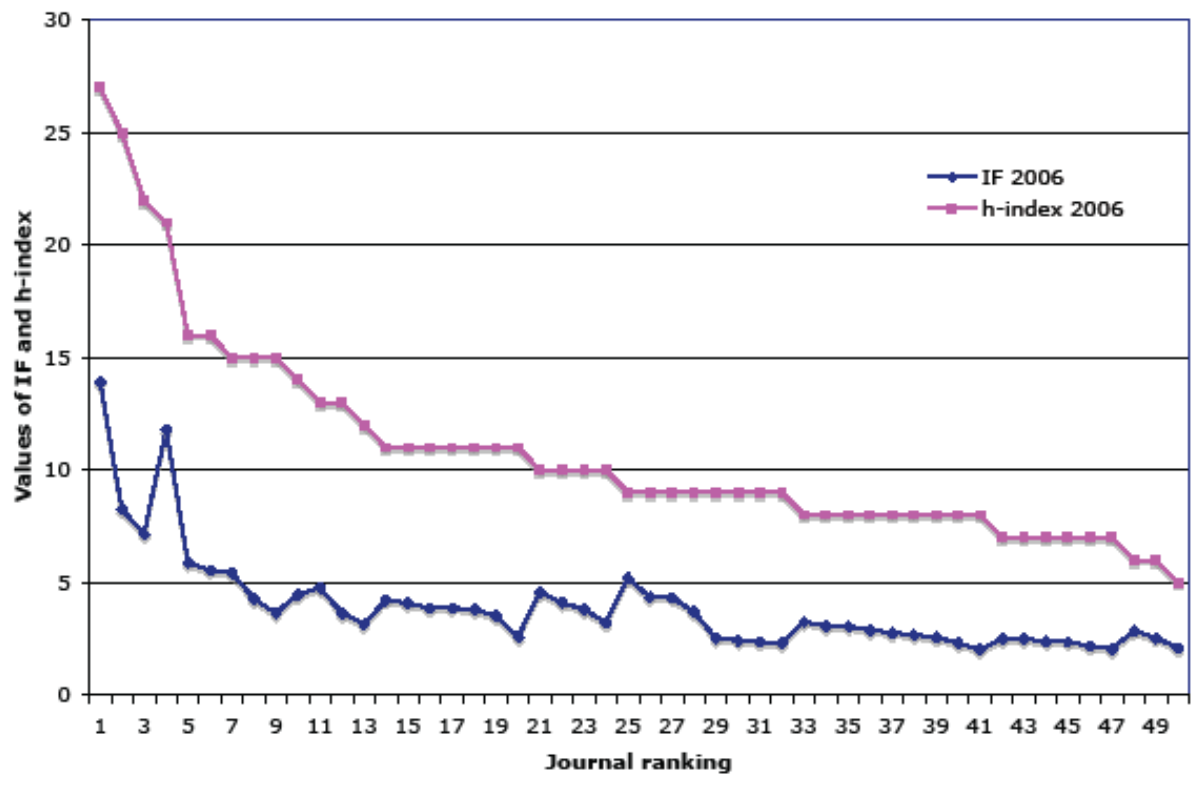

Figure 1B: Comparison of IF 2006 and h-index 2006 for Psychiatry journals (h-index ranking) 


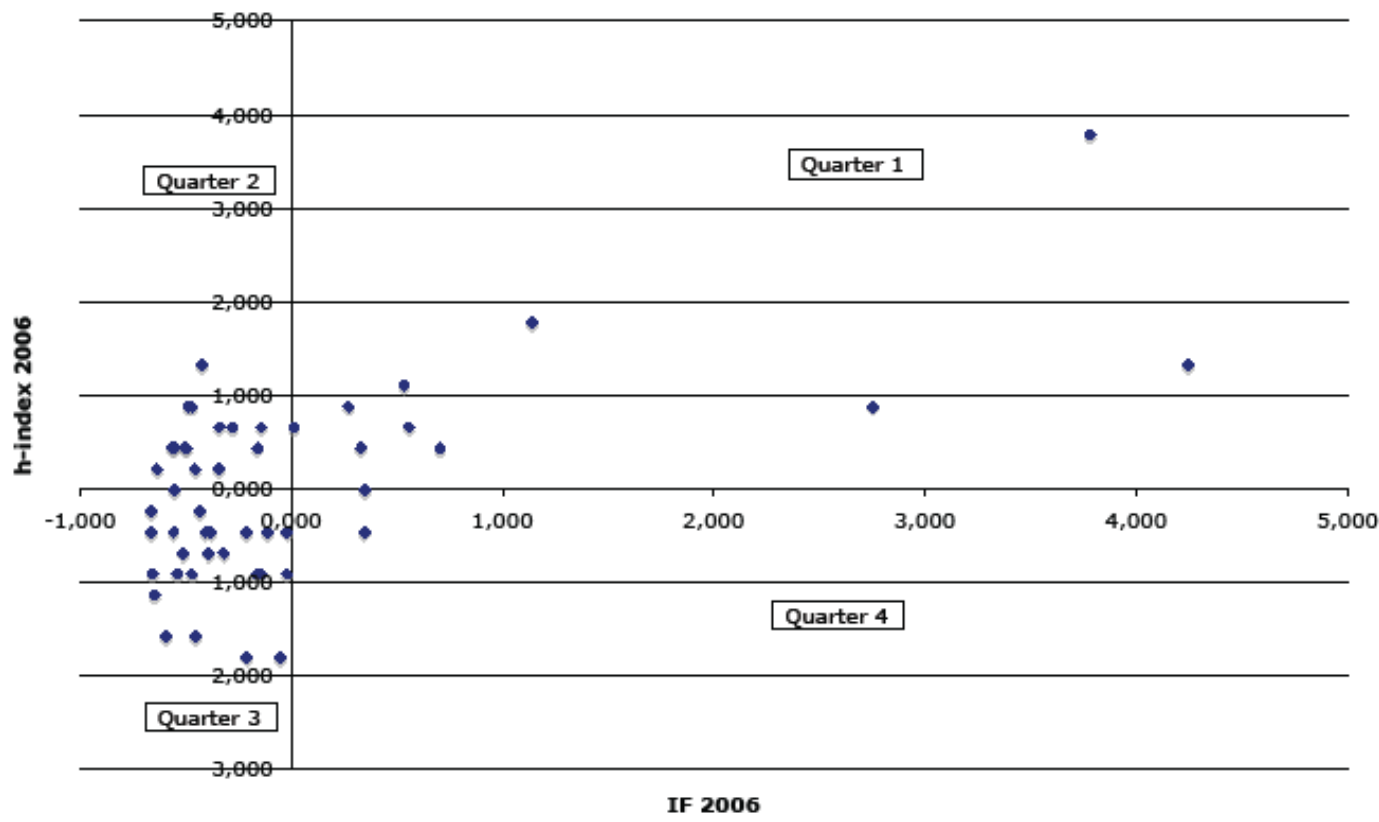

Figure 2: Standard scores of IF 2006 and h-index 2006 for Pharmacology and Pharmacy journals 


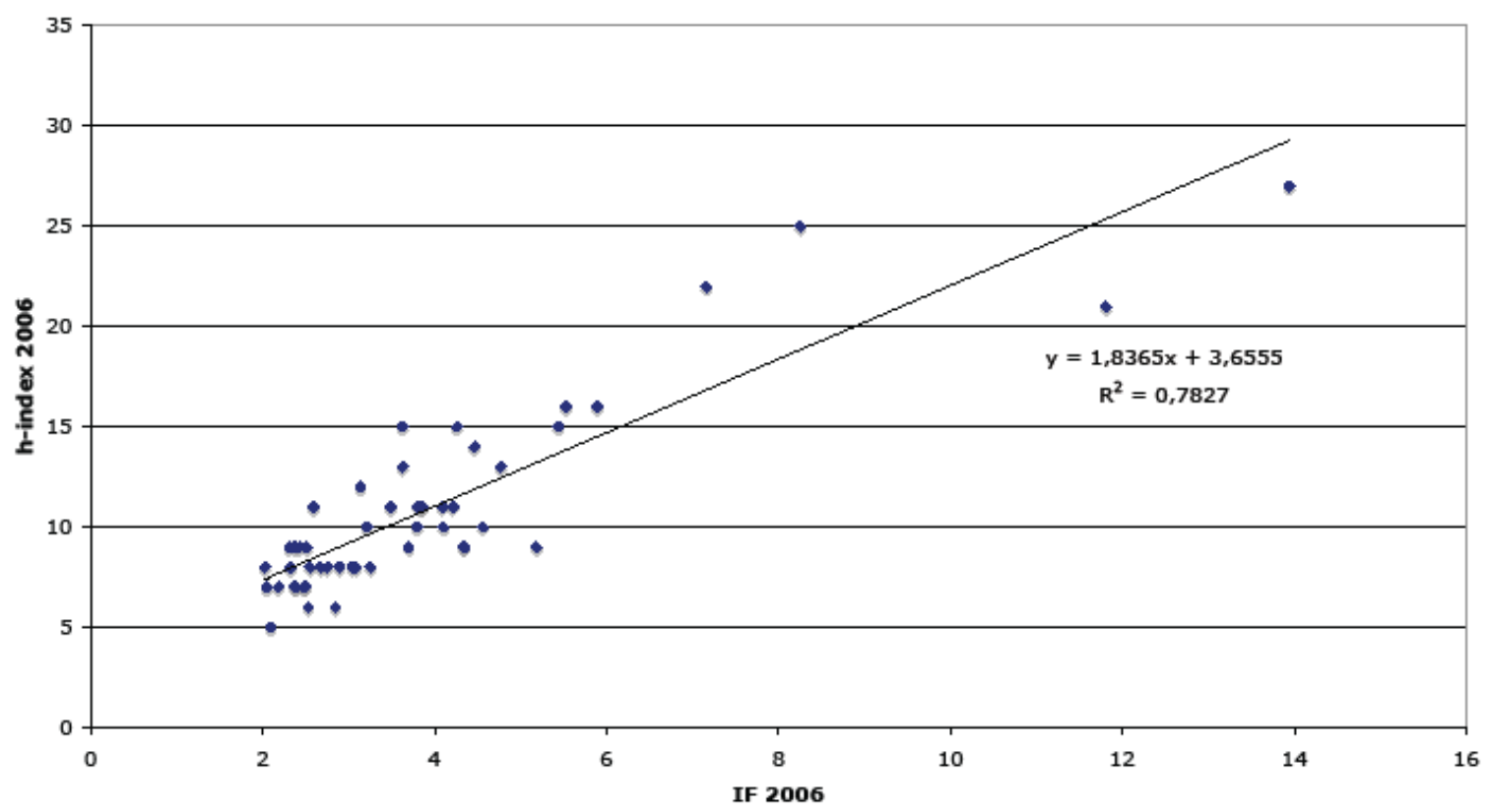

Figure 3: Correlation of IF 2006 and h-index 2006 for Psychiatry journals 


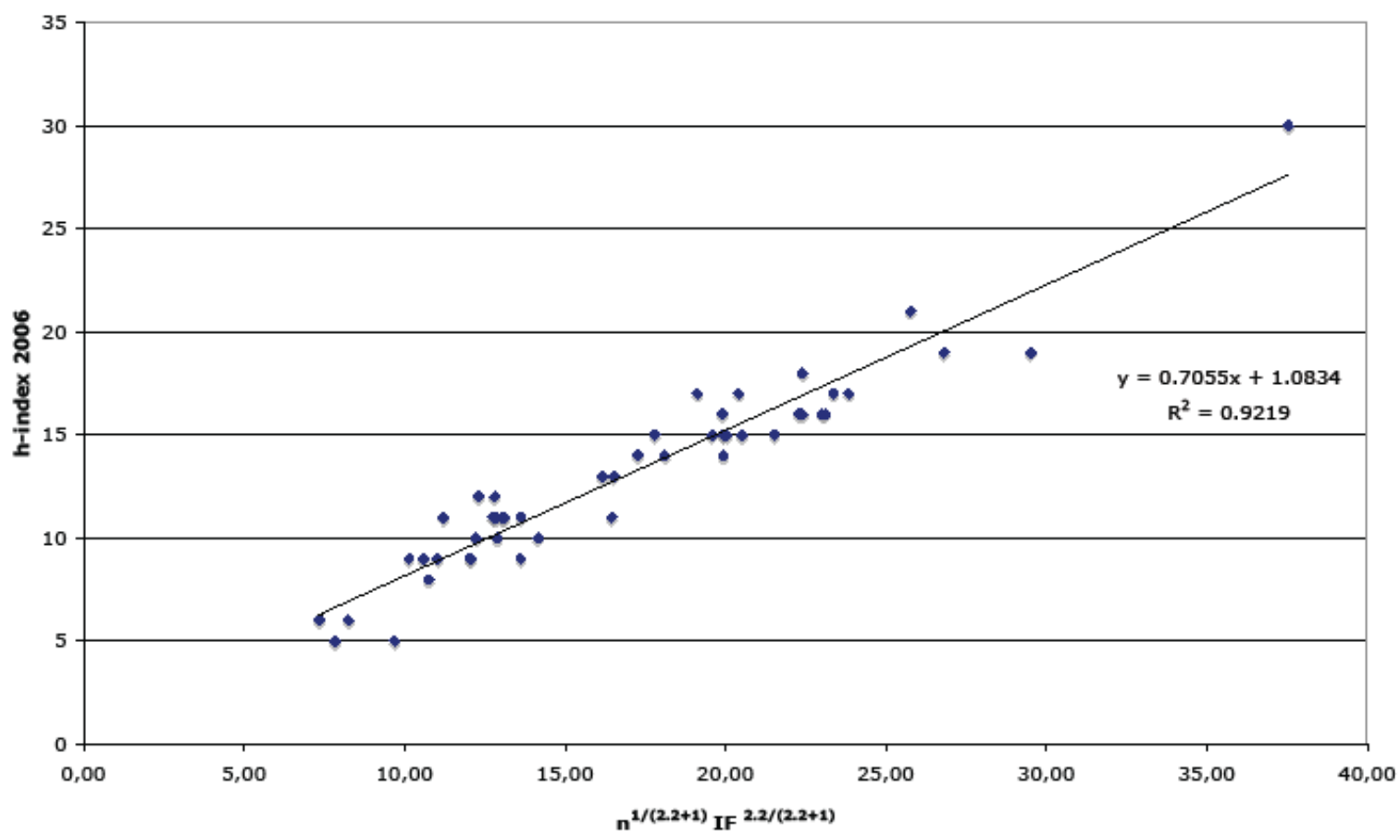

Figure 4A: Correlation of the $h$-index with $n^{1 /(2.2+1)} \mathrm{IF}^{2.2 /(2.2+1)}$ for Pharmacology and Pharmacy journals 


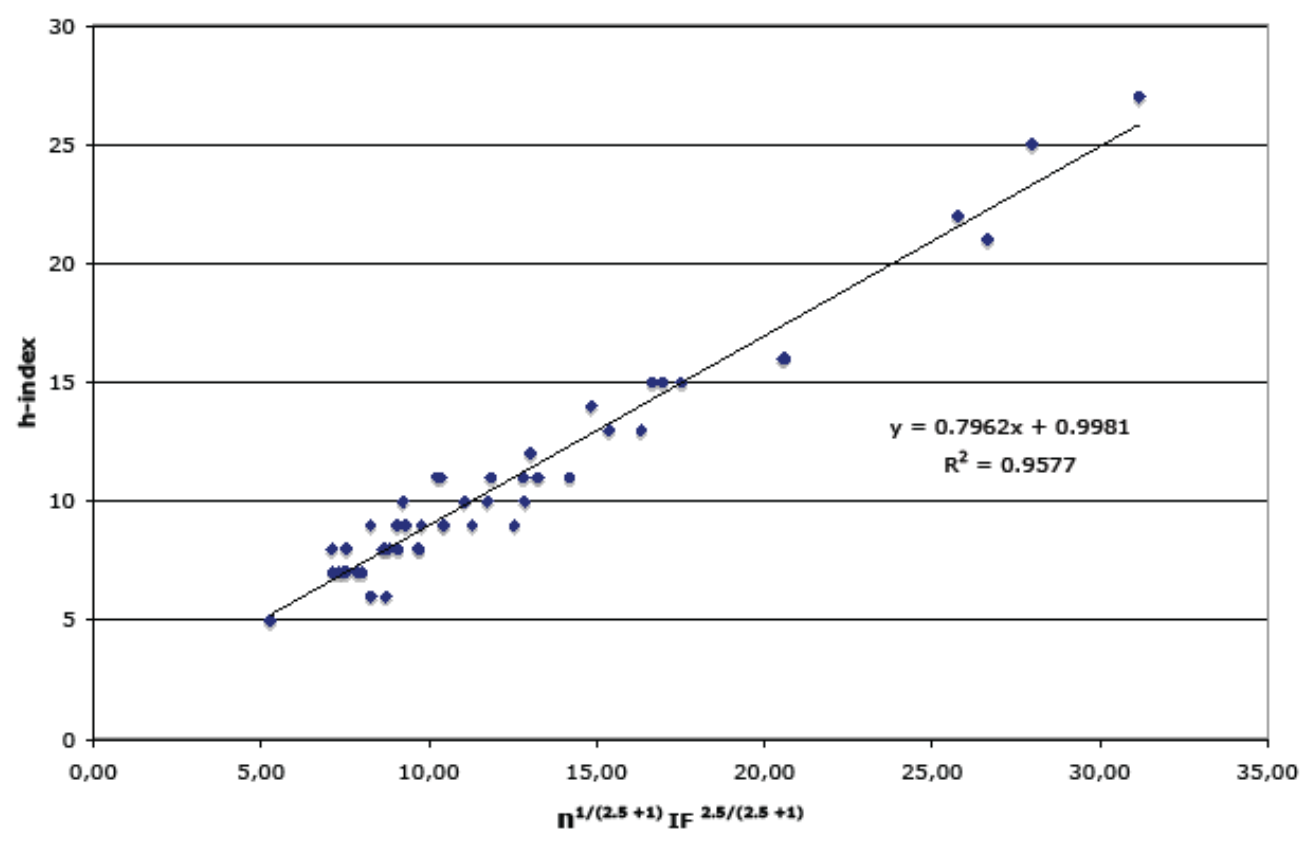

Figure 4B: Correlation of the $h$-index with $n^{1 /(2.5+1)} \quad \mathrm{IF}^{2.5 /(2.5+1)}$ for Psychiatry journals 


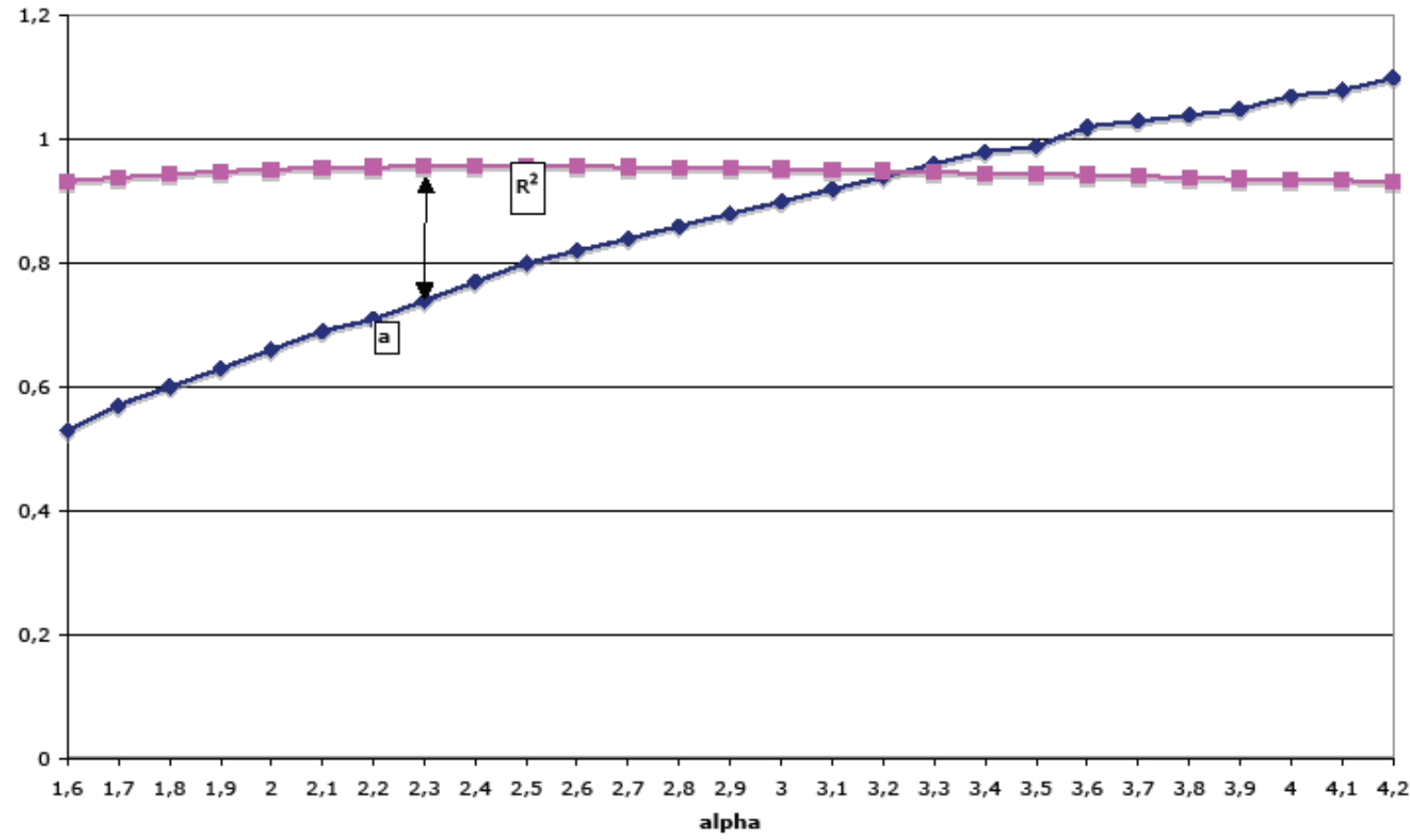

Figure 4C: Variation of $a$ and $\mathbf{R}^{2}$ according to $\alpha$ 